\title{
The Effect of Valerian and Ginger on Dysmenorrhea: A Randomized Clinical Trial
}

\author{
Masoumeh Davood Abadi ${ }^{1}$, Katayon Vakilian ${ }^{1 *}$, Nafiseh Seyyed Zadeh Aghdam ${ }^{1}$, Mehdi Ranjbaran ${ }^{2,3}$
}

\begin{abstract}
Objectives: Dysmenorrhea is a frequent complaint in young females. In recent years, researchers have grown an interest in the use of herbal drugs to decrease menstrual pain given the side effects of chemical drugs. This project was conducted to evaluate the effect of valerian and ginger on the duration of pain and analgesic use in dysmenorrhea.

Materials and Methods: This triple-blind randomized clinical trial was performed on 210 dormitory females who were randomly divided into valerian, ginger, and control groups after opening an envelope. In this study, 250 and $350 \mathrm{mg}$ of ginger and valerian in each capsule were administered, respectively, and $250 \mathrm{mg}$ sugar was used as a placebo. The number of days with pain and analgesic use were evaluated as well. Finally, descriptive (percentage and mean) and inferential ( $t$ test, post hoc, and chi-square at a significance level of 0.05) statistics were used to analyze the data.

Results: The results of the study showed a marginally significant difference in the duration of pain between ginger ( $1.61 \pm 0.64$ days) and control $(2.12 \pm 0.81$ days) groups $(P=0.052)$, and significant difference between ginger $(1.61 \pm 0.64$ days $)$ and valerian $(2.53 \pm 1.43$ days) groups $(P=0.001)$. The mean days of analgesic use among the three groups were not different significantly $(P>0.05)$. However, the mean severity of symptoms significantly differed between ginger $(0.73 \pm 0.28)$ and control $(0.3 \pm 0.04)$ groups and increased in the ginger group $(P=0.003)$.

Conclusions: In general, the administration of valerian and ginger at the doses used in this study failed to produce desirable analgesic effects and thus could not decrease the symptoms associated with dysmenorrhea

Keywords: Complementary medicine, Dysmenorrhea, Ginger, Pain, Valerian
\end{abstract}

\section{Introduction}

Dysmenorrhea is considered as a prevalent complaint among young women, which can affect their quality of life, leading to disability (1), as well as work and school (2) absenteeism in severe cases. The prevalence of dysmenorrhea is reported 50\%-90\% worldwide and up to $80 \%$ in Iran $(1,3)$. Medical treatments like prostaglandin synthesize inhibitors, non-steroidal anti-inflammatory drugs (NSAIDs), and oral contraception pills have adverse effects such as gastrointestinal effects and may be contraindicated in some women (1). Although NSAIDs effectively decrease pain, they are not very popular due to their gastrointestinal adverse reactions that are approved by the Food and Drug Administration (4). In recent years, the use of herbal drugs has received special attention regarding decreasing menstrual pain since chemical medicines have side effects $(5,6)$. Valerian is one of the herbs that has been traditionally used as a sedative and analgesic since the 11th century (7). This herb (Valeriana officinalis) is a perennial flowering plant and its roots and rhizomes are used for medicinal purposes (8). Clinical trials performed using the extract of this plant showed no complications, side effects, or sensitivity even during pregnancy and lactation $(9,10)$. In addition, its root contains different compounds including alkaloids, free amino acids (e.g., gamma-aminobutyric acid, tyrosine, arginine, and glutamine), valepotriates, and valerenic acid. Valepotriates and valerenic acid are two effective substances in the valerian root which have sedative, analgesic, and anti-stress properties. Valerian further decreases the activity of the central nervous system (CNS) through unknown mechanisms. Biochemical studies indicate that valerenic acid probably halts the enzymatic system responsible for the catabolism of gammaaminobutyric acid (GABA) temporarily which increases the concentration of GABA leading to a decrease in the activity of CNS and sedation (11).

Furthermore, ginger is another plant whose root has long been used in medicine. It has been used as antiinflammatory medicine in musculoskeletal diseases in Chinese traditional medicine for more than 2500 years. One of the traditional uses of ginger is to treat dysmenorrhoea. Moreover, gingerol and gingerdions, which are found in ginger, decrease leukotrienes and prostaglandins through the inhibition of cyclooxygenase and lipoxygenase (12). To the best of our knowledge, this

Received 20 May 2018, Accepted 14 July 2018, Available online 17 August 2018

${ }^{1}$ Department of Nursing Midwifery, Arak University of Medical Sciences, Arak, Iran. ${ }^{2}$ Department of Epidemiology, School of Public Health, Shahid Beheshti University of Medical Sciences, Tehran, Iran. 3Department of Epidemiology and Biostatistics, School of Public Health, Tehran University of Medical Sciences, Tehran, Iran.

*Corresponding Author: Katayon Vakilian, Tel: +988634173505, Email: dr.kvakilian@arakmu.ac.ir 
study was the first one that planned to assess the effect of valerian and ginger on the duration of pain, analgesic use, and the associated symptoms in dysmenorrhoea.

\section{Materials and Methods}

This blind randomized clinical trial was performed on 210 female dormitory-residing college students. The sample size was calculated as 70 participants in each group according to an alpha of $5 \%$, the power of $80 \%$, the standard deviation of 2.5 for the severity of pain, and the clinically important difference of one in addition to considering the number of the groups (3 groups).

The inclusion criteria included being single, within the age range of 20-30 years, and at the onset of menstrual pain before 20 years of age, having regular menstrual cycles of 21-35 days and menstrual bleeding without expelling clots (mild to moderate bleeding) at the onset of menstrual pain after the age of 20. Additionally, other criteria were being a known case of chronic diseases (e.g., diabetes, along with hyper and hypothyroidism), using anticoagulants, having a positive history of allergy to medicinal herbs, pelvic inflammatory diseases, and fibroids and pelvic tumours, and finally, any kind of gynaecologic surgery (laparotomy or laparoscopic surgery of cysts, tumours, and intra pelvic adhesions). On the other hand, the exclusion criteria were willingness to withdraw from the study, irregular use of the drug or the placebo, any surgery during the study, and not completing the questionnaire. Written consent was taken from all participants. Convenient sampling was used to select the study population and randomization was performed with a computer method as well.

Similarly, samplings were assigned by balanced block randomization (Blocks $\mathrm{A}, \mathrm{B}$, and $\mathrm{C}$ ). In this study, the administered dose of ginger and valerian in each capsule was 250 and $350 \mathrm{mg}$, respectively, and $250 \mathrm{mg}$ sugar was used as a placebo. A checklist, designed for the selection of the research units, was given to 250 students with dysmenorrhea. After collecting the questionnaires, 250 students were found eligible of whom 210 were selected by willing to participate and entered one of the ginger (A), valerian (B), and placebo (C) groups using a computer method. The participants were ensured that they could withdraw from the study at any stage and were requested to complete the consent form to confirm their willingness for participation. Then, the number of days with pain, analgesic use, and the associated symptoms of dysmenorrhoea were evaluated, followed by recording the daily use of analgesics. As for the pain duration, the participants were asked to mark the days they had pain in a checklist.

After filling the questionnaires, participants were randomly placed in groups $\mathrm{A}, \mathrm{B}$, and $\mathrm{C}$, and were then convinced to consume capsules containing $250 \mathrm{mg}$ ginger rhizome, $350 \mathrm{mg}$ valerian rhizome powder, and $250 \mathrm{mg}$ sugar, respectively. All three groups were requested to take one capsule every 8 hours on the first three days of menstruation for 2 consecutive menstrual cycles. Next, they completed the second questionnaire after the first and second menstruation. All drug and placebo capsules were produced in similar and coded packages by Herbi Daru Pharmaceutical Company, Tabriz, Iran. Therefore, the participants were blind to the content of the packages.

Five participants in the valerian group were excluded due to noncooperation and refusal to complete the questionnaire and four participants in the valerian group (two cases due to abdominal bloating and 2 others due to noncooperation) were excluded as well. Eventually, one participant in the placebo group was removed due to moving to a personal residence (Figure 1).

\section{Data Analysis}

The results were calculated by the mean multidimensional scoring system using one-way ANOVA in ginger, valerian, and placebo groups. Finally, the post hoc and chi-square tests were used for the comparison of 2 groups and for nominal variables at the significance level of 0.5 , respectively.

\section{Results}

The mean age of the participants was $20.36 \pm 1.28$, $21.72 \pm 1.54$, and $21.16 \pm 0.91$ years in the valerian, control, and ginger groups, respectively, which showed a significant difference $(P=0.001)$. The mean age of the participants at menarche was $12.72 \pm 0.81,13.46 \pm 1.57$, and $13.29 \pm 0.93$ years in the valerian, placebo, and ginger groups, respectively, representing a significant difference $(P=0.001)$. In addition, the mean age at the onset of dysmenorrheal was $13.89 \pm 1.27,15.75 \pm 2.55$, and $14.09 \pm 1.57$ years in the valerian, placebo, and ginger groups, respectively, indicating a significant difference $(P=0.001)$. The mean body mass index was $22.11 \pm 1.831$, $20.91 \pm 5.71$, and $26.83 \pm 12.34$ in the valerian, placebo, and ginger groups, respectively, which demonstrated a significant difference as well $(P=0.0001)$. Tables 1 and 2 show the findings of the study. Based on the results, on the third day after the first month of intervention, 51 (77.3\%), $36(52.2 \%)$, and 22 girls (33.8\%) in the valerian, placebo, and ginger groups were pain free, respectively, which showed a significant difference $(P=0.001)$ in this regard (Table 3).

\section{Discussion}

The findings of our study revealed that the duration of pain did not differ significantly among the three groups in the first month but showed a significant difference in the second month. In other words, the duration of pain was significantly shorter in the ginger group as compared to valerian and placebo groups. On the other hand, our results demonstrated that more participants were pain free in the valerian group on the third day of the first and second months as compared to the other two groups with a significant difference. A study conducted by Ozgoli et al 


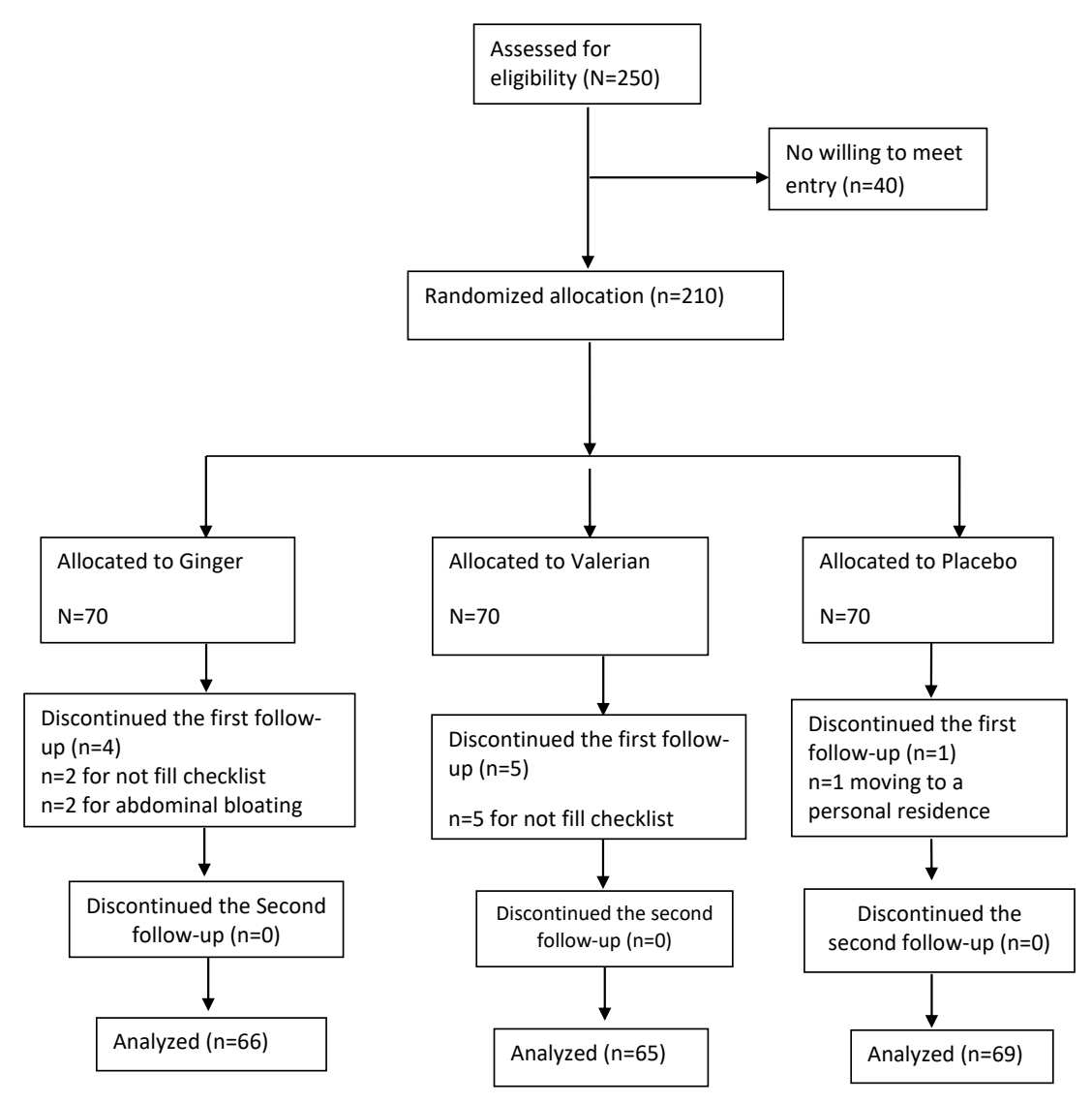

Figure 1. Flowchart of the study.

further showed that ginger was effective in the first month. The difference between our findings and the results of the above-mentioned study might be due to the frequency of drug administration in the intervention group since they used $250 \mathrm{mg}$ ginger four times a day while the participants of the present study were administered the same dose three times daily. The excess dose may have resulted in more inhibition of prostaglandins, leading to the analgesic effects of the ginger (13). Furthermore, this study was conducted on the duration of pain while Ozgoli et al examined pain severity. Therefore, this study confirmed that the ginger can be used to diminish pain duration in dysmenorrhea. The other study on 100 female students with moderate to severe primary dysmenorrhea in 2 groups of ginger and mefenamic acid showed that $250 \mathrm{mg}$ capsules of mefenamic acid every eight hours, and

Table 1. The Mean Duration of Pain in the First and Second Months After Intervention in Valerian, Ginger, and Placebo Groups

\begin{tabular}{|c|c|c|c|c|}
\hline & Group & Mean \pm SD & $\mathrm{Cl}$ & $P$ Value ${ }^{*}$ \\
\hline \multirow{6}{*}{ Duration of pain in the first month (day) } & Valerian- & $2.13 \pm 1.56$ & \multirow{2}{*}{$-0.316,0.818$} & \multirow{2}{*}{0.548} \\
\hline & Ginger & $1.88 \pm 0.64$ & & \\
\hline & Valerian- & $2.13 \pm 1.56$ & \multirow{2}{*}{$-0.682,0.511$} & \multirow{2}{*}{0.938} \\
\hline & Placebo & $2.05 \pm 0.94$ & & \\
\hline & Ginger & $1.88 \pm 0.64$ & \multirow{2}{*}{$-0.755,0.425$} & \multirow{2}{*}{0.785} \\
\hline & Placebo & $2.05 \pm 0.94$ & & \\
\hline \multirow{6}{*}{ Duration of pain in the second month (day) } & Valerian- & $2.53 \pm 1.43$ & \multirow{2}{*}{$0.409,1.426$} & \multirow{2}{*}{0.001} \\
\hline & Ginger & $1.61 \pm 0.64$ & & \\
\hline & Valerian- & $2.53 \pm 1.43$ & \multirow{2}{*}{$-0.938,0.113$} & \multirow{2}{*}{0.154} \\
\hline & Placebo & $2.12 \pm 0.81$ & & \\
\hline & Ginger & $1.61 \pm 0.64$ & \multirow{2}{*}{$-1.019,0.010$} & \multirow{2}{*}{0.052} \\
\hline & Placebo & $2.12 \pm 0.81$ & & \\
\hline
\end{tabular}

Note. *Post hoc test; $\mathrm{Cl}$ : Confidence interval; SD: Standard deviation. 
Table 2. The Mean Days of using Analgesic in the First and Second Months After Intervention in Valerian, Placebo, and Ginger Groups

\begin{tabular}{|c|c|c|c|c|}
\hline & Group & Mean \pm SD & $\mathrm{Cl}$ & $P$ Value ${ }^{*}$ \\
\hline \multirow{6}{*}{ Amount of administered analgesic in the first month } & Valerian- & $2.19 \pm 2.27$ & \multirow{2}{*}{$-1.347,0.346$} & \multirow{2}{*}{0.345} \\
\hline & Ginger & $2.69 \pm 0.280$ & & \\
\hline & Valerian- & $2.19 \pm 2.27$ & \multirow{2}{*}{$-0.115,1.553$} & \multirow{2}{*}{0.107} \\
\hline & Placebo & $1.478 \pm 1.562$ & & \\
\hline & Ginger & $2.69 \pm 0.280$ & \multirow{2}{*}{$0.381,2.056$} & \multirow{2}{*}{0.002} \\
\hline & Placebo & $1.478 \pm 1.562$ & & \\
\hline \multirow{6}{*}{ Amount of administered analgesic in the second month } & Valerian- & $1.84 \pm 2.11$ & \multirow{2}{*}{$-1.200,0.497$} & \multirow{2}{*}{0.592} \\
\hline & Ginger & $2.20 \pm 2.48$ & & \\
\hline & Valerian- & $1.84 \pm 2.11$ & \multirow{2}{*}{$-0.374,1.298$} & \multirow{2}{*}{0.394} \\
\hline & Placebo & $1.38 \pm 1.47$ & & \\
\hline & Ginger & $2.20 \pm 2.48$ & \multirow{2}{*}{$-0.026,1.653$} & \multirow{2}{*}{0.061} \\
\hline & Placebo & $1.38 \pm 1.47$ & & \\
\hline
\end{tabular}

Note. *Post hoc test; Cl: Confidence interval; SD: Standard deviation.

Table 3. Frequency of Dysmenorrhea on the Third Day of the Second Month of Intervention in Valerian, Placebo, and Ginger Groups

\begin{tabular}{lcccc}
\hline & \multicolumn{1}{c}{ Group } & \multirow{2}{*}{ Total } & \multicolumn{1}{c}{$\boldsymbol{P}$ Value } \\
\cline { 2 - 4 } Pain & Valerian, No. (\%) & Ginger, No. (\%) & Placebo, No. (\%) & \\
No pain & $51(77.3)$ & $22(33.8)$ & $36(52.2)$ & $109(54.5)$ \\
Pain & $15(22.7)$ & $43(66.2)$ & $33(47.8)$ & $91(45.5)$ \\
Total & $66(100.0)$ & $65(100.0)$ & $69(100.0)$ & $200(100.0)$ \\
\hline
\end{tabular}

Note. ${ }^{*} \chi 2$ test.

$250 \mathrm{mg}$ capsules (zintoma) every 6 hours in a sequence of two-month usage decreased the intensity of pain within the groups by time, but not between the groups (14). Likewise, Chen et al (15) reviewed five full-text articles about the comparison of oral ginger and mefenamic acid in pain relief dysmenorrhea. After meta-analysis, no significant difference was found between ginger and mefenamic acid as an NSAID. Moreover, Shirooye et al (16) in a randomized trial study on 70 female students with moderate and severe primary dysmenorrhea found that the oral group receiving $250 \mathrm{mg}$ capsules of ginger powder had more pain duration compared to the group who received the topical 5 drops of ginger oil $(P=0.001)$. The reduction of mefenamic consumption was higher in the topical compared to $0.5( \pm 1.3)$ in the oral group $(P=0.006)$. The other studies showed that dysmenorrhea was better by ginger, but they did not focus on the duration of pain $(3,5)$.

Ginger may have anti-inflammatory properties due to cyclooxygenase and lipoxygenase inhibition and the consequent decrease in leukotrienes and prostaglandins (17). Our study showed that the use of analgesics not only did not decrease in the first month but also increased in the ginger group as compared to the placebo and valerian groups.

However, Mirabi et al reported that valerian decreased the use of analgesics and recommended the use of valerian instead of NSAIDs due to their side effects such as gastrointestinal problems like nausea, dyspepsia, vomiting, renal toxicity manifested as nephritic syndrome, gastric ulcer and bleeding, bleeding in other body organs, vertigo, and the like (9). In this study, analgesic consumption in valerian was less than ginger. Another study demonstrated that valerian and diazepam had similar anxiolytic and sedative effects (10). During menstruation, prostaglandins not only cause contractions in the uterus smooth muscle but also contract smooth muscles in other parts of the body like the bronchioles, intestine, and blood vessels causing dyspnea, diarrhea, and hypertension, respectively (18). Gilani et al concluded that valerian caused the relaxation of spontaneous contractions (the antispasmodic effects of valerian) in rabbit and guinea pig jejunum and ileum preparations (19).

\section{Conclusions}

In general, the administration of valerian and ginger at the suggested doses in this study produced no desirable analgesic effects. Thus, further studies are suggested in this regard. This study only investigated the female students who lived in dormitories, which is considered as a limitation. Therefore, the inclusion of participants from other contexts is recommended for future studies. Finally, other studies focusing on the effect of valerian on dysmenorrhea are suggested given the limited body of research in this regard.

\section{Conflict of Interests}

The authors declare no conflict of interests. 


\section{Ethical Issues}

This study was registered in the Clinical Registry of Clinical Trials (Registration code: IRCT138903053291N2) by the ethical code of 3-74-88. Written informed consent was obtained from all students.

\section{Financial Support}

Arak University of Medical Sciences supported the study.

\section{Acknowledgements}

The authors wish to thank the Deputy of Research and all the people who helped us to conduct this study.

\section{References}

1. Berek JS. Berek \& Novak's Gynecology. 16th ed. Philadelphia: Lippincott Williams \& Wilkins; 2016:456-460.

2. Tu F. Dysmenorrhea: contemporary perspectives. Pain. 2007;15(8):1-4.

3. Tavallaee M, Joffres MR, Corber SJ, Bayanzadeh M, Rad MM. The prevalence of menstrual pain and associated risk factors among Iranian women. J Obstet Gynaecol Res. 2011;37(5):442-451. doi:10.1111/j.1447-0756.2010.01362.x

4. Habibi N, Huang MS, Gan WY, Zulida R, Safavi SM. Prevalence of primary dysmenorrhea and factors associated with its intensity among undergraduate students: a crosssectional study. Pain Manag Nurs. 2015;16(6):855-861. doi:10.1016/j.pmn.2015.07.001

5. Rahnama P, Montazeri A, Huseini HF, Kianbakht S, Naseri M. Effect of Zingiber officinale R. rhizomes (ginger) on pain relief in primary dysmenorrhea: a placebo randomized trial. BMC Complement Altern Med. 2012;12:92. doi:10.1186/1472-6882-12-92

6. Chen HY, Lin YH, Su IH, Chen YC, Yang SH, Chen JL. Investigation on Chinese herbal medicine for primary dysmenorrhea: implication from a nationwide prescription database in Taiwan. Complement Ther Med. 2014;22(1):116-125. doi:10.1016/j.ctim.2013.11.012

7. Kashefi F, Khajehei M, Tabatabaeichehr M, Alavinia M, Asili J. Comparison of the effect of ginger and zinc sulfate on primary dysmenorrhea: a placebo-controlled randomized trial. Pain Manag Nurs. 2014;15(4):826-833. doi:10.1016/j. pmn.2013.09.001

8. DerMarderosian A, Beutler JA. The review of natural products: the most complete source of natural product information. Philadelphia: Lippincott Williams \& Wilkins; 2012:458-460.
9. Mirabi P, Dolatian M, Mojab F, Majd HA. Effects of valerian on the severity and systemic manifestations of dysmenorrhea. Int J Gynaecol Obstet. 2011;115(3):285-288. doi:10.1016/j.ijgo.2011.06.022

10. Murphy K, Kubin ZJ, Shepherd JN, Ettinger RH. Valeriana officinalis root extracts have potent anxiolytic effects in laboratory rats. Phytomedicine. 2010;17(8-9):674-678. doi:10.1016/j.phymed.2009.10.020

11. Miyasaka LS, Atallah AN, Soares BG. Valerian for anxiety disorders. Cochrane Database Syst Rev. 2006(4):CD004515. doi:10.1002/14651858.CD004515.pub2

12. Ho SC, Chang KS, Lin CC. Anti-neuroinflammatory capacity of fresh ginger is attributed mainly to 10-gingerol. Food Chem. 2013;141(3):3183-3191. doi:10.1016/j. foodchem.2013.06.010

13. Ozgoli G, Goli M, Moattar F. Comparison of effects of ginger, mefenamic acid, and ibuprofen on pain in women with primary dysmenorrhea. J Altern Complement Med. 2009;15(2):129-132. doi:10.1089/acm.2008.0311

14. Shirvani MA, Motahari-Tabari N, Alipour A. The effect of mefenamic acid and ginger on pain relief in primary dysmenorrhea: a randomized clinical trial. Arch Gynecol Obstet. 2015;291(6):1277-1281. doi:10.1007/s00404-0143548-2

15. Chen CX, Barrett B, Kwekkeboom KL. Efficacy of oral ginger (Zingiber officinale) for dysmenorrhea: a systematic review and meta-analysis. Evid Based Complement Alternat Med. 2016;2016:6295737. doi:10.1155/2016/6295737

16. Shirooye P, Hashem-Dabaghian F, Hamzeloo-Moghadam M, Afrakhteh M, Bioos S, Mokaberinejad R. A clinical comparative study of oral and topical ginger on severity and duration of primary dysmenorrhea. Research Journal of Pharmacognosy. 2017;4(1):23-32.

17. Daily JW, Zhang X, Kim DS, Park S. Efficacy of ginger for alleviating the symptoms of primary dysmenorrhea: a systematic review and meta-analysis of randomized clinical trials. Pain Med. 2015;16(12):2243-2255. doi:10.1111/ pme. 12853

18. Andreatini R, Sartori VA, Seabra ML, Leite JR. Effect of valepotriates (valerian extract) in generalized anxiety disorder: a randomized placebo-controlled pilot study. Phytother Res. 2002;16(7):650-654. doi:10.1002/ptr.1027

19. Gilani AH, Khan AU, Jabeen Q, Subhan F, Ghafar R. Antispasmodic and blood pressure lowering effects of Valeriana wallichii are mediated through $\mathrm{K}+$ channel activation. J Ethnopharmacol. 2005;100(3):347-352. doi:10.1016/j.jep.2005.05.010

(c) 2020 The Author (s); This is an open-access article distributed under the terms of the Creative Commons Attribution License (http://creativecommons.org/licenses/by/4.0), which permits unrestricted use, distribution, and reproduction in any medium, provided the original work is properly cited. 